\title{
Globalization And Education: Challenges And Opportunities
}

Sadegh Bakhtiari, (Email: bakhtiari_sadegh@yahoo.com), Isfahan University, Iran H. Shajar, Isfahan University, Iran

\begin{abstract}
The impact of globalization on culture and educational system is a major concern. Some people saw it as a treat for traditional institutions such as the family and the school, another argument saw benefits in overturning traditional and developing modern attitudes. this paper will analysis the positive and negative impacts of globalization on education for developing countries. Effective education systems are the foundation of opportunities to lead a decent life. Ensuring that all children have adequate access to education is essential public sector function for countries at all income level. The paper argues that education is a core element of society, and the foundation of democratic choice. The large difference in opportunities in education between countries is one of the basic causes of global inequality. People can only contribute and benefit from globalization if they are endowed with knowledge, skills, and values and with the capabilities and rights needed to pursue their basic likelihoods.
\end{abstract}

\section{INTRODUCTION}

lobalization is a complex phenomenon that has had far-reaching effects. Not surprisingly, therefore, the term "globalization" has acquired many emotive connotations. At one extreme, globalization is seen as an irresistible and benign force for delivering economic prosperity to people throughout the world. At the other, it is blamed as a source of all contemporary ills.

To different scholars, the definition of globalization may be different. According to Cheng (2000), it may refer to the transfer, adaptation, and development of values, knowledge, technology, and behavioral norms across countries and societies in different parts of the world. The typical phenomena and characteristics associated with globalization include growth of global networking (e.g. internet, world wide e-communication, and transportation), global transfer and interflow in technological, economic, social, political, cultural, and learning areas, international alliances and competitions, international collaboration and exchange, global village, multi-cultural integration, and use of international standards and benchmarks. UNDP in Human Development Report (1999) describes globalization as the increasing interdependence of the world's inhabitants, on an economic, technological, cultural, as well as political level. It is seen as a general tendency towards the liberalization of economic trade, a wider circulation of capital, goods and products, and a quasi-abolition of national borders. The speed of communication and the relatively low cost of processing information have caused distances to be eliminated. The categories of time and space have been completely overturned. Models of consumption, values, and standardized cultural products thus tending to make behaviors and attitudes more similar and wipe out differences across the globe.

\section{GLOBALIZATION, EDUCATION AND LIFELONG LEARNING}

People can only contribute and benefit from globalization if they endowed with knowledge, skills and with the capabilities and rights needed to pursue their basic livelihoods. They need employment and incomes, and a healthy environment. These are the essential conditions which empower them to participate fully as citizens in their local, national and global communities. These goals, can only be reached if national governments allocate adequate resources to education, basic infrastructure and the environment, and create the institutional framework which ensures broad access and opportunity. 
Education is a major concern for all societies. As the foundation and essential driving force of economic, social, and human development, education is at the heart of the change that is dramatically affecting our world in the areas of science, technology, economics, and culture. It is the reason behind social change and scientific progress, and in its turn, it is subjected to the results of progress that it itself has engendered, both with regard to content as well as methods and established aims.

In spite of the aforementioned facts, some people argue that education systems no longer seem to take into account the new needs confronting people everywhere in the world. For example, René Bendit and Wolfgang Gaiser make the following observation on the education system in the United States of America, which could be applied to many countries in the world :

The education system has failed to meet current social challenges. The increase in youth problems such as a problematic transition to the working world, increasing poverty, teen age pregnancies, drug abuse, intolerance towards minorities, juvenile delinquency and violence, are treated as a reflection of the fact that schools are no longer have any connection with the real life world. ${ }^{1}$

In order to integrate into the world economy, people must not only acquire the knowledge and tools of traditional knowledge, but above all, they must be capable of acquiring new skills demanded by a knowledge society. Indeed, the resulting rapid change in technological and scientific knowledge make learning a permanent process, a lifelong learning process in the words of the Report of the International Commission on Education for the 21st Century to UNESCO, entitled: Learning, the treasure within. ${ }^{2}$

Lifelong learning is based on the following four fundamental precepts:

- $\quad$ Learning to know, by combining a sufficiently broad general knowledge with the opportunity to work in depth on a small number of subjects. This also means learning to learn, so as to benefit from the opportunities education provides throughout life.

- $\quad$ Learning to do, in order to acquire not only an occupational skill but also, more broadly, the competence to deal with a large number of situations and work in teams. It also means learning to do in the context of young people's various social and work experiences which may be informal, as a result of the local or national context, or formal, involving courses alternating study and work.

- Learning to live together, by developing an understanding of other people and an appreciation of interdependence, - carrying out joint projects and learning to manage conflicts - in a spirit of respect for the values of pluralism, mutual understanding and peace.

- Learning to be, so as to develop better one's personality and be able to act with increasingly greater autonomy, judgment, and personal responsibility. To that end, education must not disregard any aspect of a person's potential: memory, reasoning, aesthetic sense, physical capacities, and communication skills.

\section{SOME POSITIVE AND NEGATIVE IMPACTS OF GLOBALIZATION}

Although globalization seems to be unavoidable to many countries and numerous initiatives and efforts have been made to adapt to it with aims at taking the opportunities created from it to develop their societies and people, in recent years there are also increasing international concerns with the dangerous impacts of globalization on indigenous and national developments. Various social movements have been initiated against the threats of globalization particularly in developing countries. The negative impacts of globalization include various types of economic, political, and cultural colonization by advanced countries on those developing and under-developed countries. Inevitably, how to maximize the opportunities and benefits from globalization to support local developments and reduce the threats and negative impacts of globalization will be the major concerns of developing countries.

As mentioned above, globalization is creating opportunities for sharing knowledge, technology, social values, and behavioral norms and promoting developments at different levels including individuals, organizations, communities, and societies across different countries and cultures. In particular, the advantages of globalization may include the following. ${ }^{3}$ 
- Global sharing of knowledge, skills, and intellectual assets that are necessary to multiple developments at different levels;

- Mutual support, supplement and benefit to produce synergy for various developments of countries, communities, and individuals;

- $\quad$ Creating values and enhancing efficiency through the above global sharing and mutual support to serving local needs and growth;

- $\quad$ Promoting international understanding, collaboration, harmony, and acceptance to cultural diversity across countries and regions.

- $\quad$ Facilitating communications, interactions, and encouraging multi-cultural contributions at different levels among countries.

At the same time, globalization, potentially creating serious negative impacts for developing and underdeveloped countries. This is also the major reason why there have been so many ongoing social movements in different parts of the world against the trends of globalization particularly in economic and political areas. The potential negative impacts of globalization are various types of political, economic, and cultural colonization and overwhelming influences of advanced countries to developing countries and rapidly increasing gaps between rich areas and poor areas in different parts of the world. In particular, the potential negative impacts include the following:

- Increasing the technological gaps and digital divides between advanced countries and less developed countries;

- $\quad$ Creating more legitimate opportunities for a few advanced countries for a new form of colonization of developing countries;

- $\quad$ Increasing inequalities and conflicts between areas and cultures; and

- $\quad$ Promoting the dominant cultures and values of some advanced areas.

\section{GLOBALIZATION AND UNEQUAL ACCESS TO EDUCATION}

Many people believe that, education is one of key local factors that can be used to moderate some impacts of globalization from negative to positive and convert threats into opportunities for the development of individuals and local community in the inevitable process of globalization. How to maximize the positive effects and minimize the negative impacts of globalization is a major concern in current educational reform for national and given the phenomenon of "globalization", economic growth of the last decades has been accompanied by a worsening of inequalities in the world and in particular, inequalities of access to knowledge.

Integration into world economy today's implies not only mastery of traditional knowledge but also the capacity to acquire the new skills required by a knowledge society. It is therefore evident that an unequal sharing of the new communication and information technologies only serves to reinforce existing inequalities.

While education deficits are obviously greater in developing countries, this is a major issue in developed countries as well. In many industrialized countries there is a persistent problem of illiteracy and low skills, which is an important source of social exclusion. Unequal access to education also fuels growing wage inequality and worsen the income distribution. The uneducated and unskilled in industrialized countries face severe disadvantage in an increasingly competitive global market.

However, the provision of both primary and secondary schooling increased during the 90s across the globe, but progress is inadequate and hides the differences between countries and regions. The OECD countries, for example, spend 100 times more per pupil in primary and secondary education than low-income countries. There are many evidences indicate that the more rapid progress is possible if the political will and the resources exist, in high- and low-income countries alike.

All countries which have benefited from globalization have invested significantly in their education and training systems. Today women and men need broad based skills which can be adapted to rapidly changing economic requirements as well as appropriate basic skills which enable them to benefit from information technology, increasing their ability to overcome barriers of distance and budgetary limitations. While Internet technology is not particularly 
capital-intensive, it is very human capital-intensive. Sound education policy also provides an important instrument to offset the negative impacts of globalization, such as increasing income inequalities, with effects which may ultimately be stronger than labour market policies.

Education is a core element of society, and the foundation of democratic choice. The large differences in opportunities in education between countries are one of the basic causes of global inequality. Furthermore, international migration allows rich countries to benefit from the investments in human capital made in poor countries - giving them a responsibility to support the education systems where those investments are made.

The development of a national qualifications framework is also an important foundation for participation in the global economy, since it facilitates lifelong learning, helps match skill demand and supply, and guides individuals in their choice of career. Access to training and skills development for women is often hindered by family commitments, indicating a need for childcare facilities and possibilities for distance learning. Other priorities include recognition and upgrading of skills for workers in the informal economy and the adaptation of training to accommodate workers with no formal education.

\section{GLOBALIZATION, EDUCATION, AND TECHNOLOGICAL GAP}

In today's global economy and information society, knowledge and information are the keys to social inclusion and productivity, and connectivity is the key to global competitiveness. Yet in our unequal world the networked economy is able to incorporate all that it regards as valuable, but also to switch off people and parts of the world that do not fit the dominant model.

Technological capability is essential. Countries need the communications infrastructure and the production system which can process and use information for development; and people must have access to the knowledge and the ability to use it, in order to participate, take advantage of and be creative in the new technological environment. That puts education and skills at the centre of a fair and inclusive globalization.

Online distance learning could become a powerful tool for developing countries - reducing the need for expensive physical infrastructure for tertiary and vocational educational facilities and enabling investments to be made instead in communications equipment, with curricula and teaching provided through regional initiatives. The Global Distance Learning Network (GDLN) is one such initiative. It is a worldwide network of institutions which are developing and applying distance learning technologies and methods with a focus on development and poverty reduction. Such networks are likely to play an important role in building technological capabilities by:

- Increasing the technological gaps and digital divides between advanced countries and less developed countries that are hindering equal opportunities for fair global sharing.

- Global sharing of knowledge, skills, and intellectual assets that are necessary to multiple developments at different levels.

- $\quad$ Creating more legitimate opportunities for a few advanced countries to economically and politically colonize other countries globally.

- Mutual support, supplement, and benefit to produce synergy for various developments of countries, communities, and individuals.

- $\quad$ Exploiting local resources and destroying indigenous cultures of less advanced countries to benefit a few advanced countries.

- $\quad$ Creating values and enhancing efficiency through the above global sharing and mutual support to serving local needs and growth. Increasing inequalities and conflicts between areas and cultures.

ILO argues that promoting international understanding, collaboration, harmony, and acceptance to cultural diversity across countries and regions by promoting the dominant cultures and values of some advanced areas and

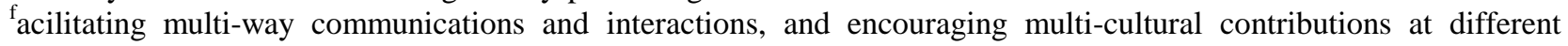
levels among countries. Clearly, the management and control of the impacts of globalization are related to some complicated macro and international issues that may be far beyond the scope of this paper. 
The increase in poverty in the world is the most tragic phenomenon in this era of abundance. It is the cause of marginalization and the exclusion of increasingly bigger groups of the world population and in particular, affects children, the young, and women. As a consequence, we see the development of cultures of poverty and marginalization that lock the same people into the cycle of poverty and reinforce their exclusion.

But it is still the inequality with regard to knowledge that constitutes one of the biggest challenges of our societies. The traditional raw materials and non renewable natural resources under threat of extinction no longer occupy the most important place in the process of production and development. It is knowledge in itself that has become one of the key resources of economic growth. We thus see a new category of workers appearing on the scene, "knowledge workers". Without knowledge, you are subject to marginalization and progressive exclusion, but the corollary is also true. "The higher the level of education and training of a country's population, the more chances a nation has of seizing opportunities and minimizing the social cost of technological change and the transition towards a more open economy".

\section{GLOBALIZATION, EDUCATION AND HUMAN RIGHTS}

Education has been proclaimed an integral part of human rights: "It must be free and compulsory with regards to basic, elementary teaching. Vocational and technological teaching must be widely available and access to higher education available to all equally, on the basis of merit." ${ }^{6}$ Education is also the driving force behind economic growth and human and cultural development. The application of policies of compulsory basic education for all and investment in quality teaching have meant governments and experts have been able to measure the impact on populations and the society as a whole. That impact can be seen in improvement in health, lowering of the rate of demographic growth, reduction of child mortality and increase in life expectancy. Education also means that populations become aware of their rights and obligations as citizens and are thus able to participate actively in the construction and management of life in their communities.

According to studies undertaken by UNESCO as well as by UNDP, the world economic crisis, which dominated the eighties, spread in virtue of the constraints imposed by economic globalization. It was also pointed out that "the process of restructuring and social adjustment that have taken place in most countries and are still taking place in some, seem to have had a lasting effect on national politics at the expense of education." ${ }^{, 7}$ The education sector has not yet acquired the right to benefit from special treatment or to be exonerated from the application of policies limiting public expenditure in general.

\section{CONCLUDING REMARKS}

This paper tries to highlights the fact that economic policies in most of the world rarely considered education as investment for the future or as a key to development, and even less as a fundamental right of human beings. The repercussions of these policies at all levels of education systems in the world, with the exception of a few industrialized countries, have been sorely felt. Such repercussions include the worsening of teaching conditions; insufficient numbers of school establishments and increase in numbers per class, particularly in developing countries experiencing strong demographic growth; the loss of teaching quality often due to the qualification level of the teacher's and the material conditions in which they carry out their profession; and finally, the loss of relevance regarding the education programs themselves. But still remains many questions, such as:

- What is education for the 21 st. century? The present-day crisis in conventional education systems is only the syndrome of a society undergoing profound change. Its political, economic, and cultural institutions and the values and symbols at the heart of those institutions, have become inoperable and obsolete in their regulatory and integrating function concerning the same individual members of the society in question.

- How can education respond to the challenges of increasing poverty, unemployment, and exclusion in the world and to those of intolerance and violence that affect all societies and are even to be found within schools themselves? 
- How can education answer the needs of a multicultural society which, in virtue of the cultural and ethnic diversity of that society's people, requires recognition of that diversity and of the people's own particular needs, and at the same time favor their social and economic integration into the majority culture?

- How can the trends towards globalization, standardization, and the homogenization of cultural models be conciliated? And how can we conciliate the increasingly strong claims for cultural diversity which, in their most extreme form, can be seen as a relinquishment of identity, the violent rejection of the other, and fundamentalism of all kinds?

In its new guise, continuing education is seen as going far beyond what is already practiced, particularly in the developed countries, namely, upgrading and refresher training, retraining and conversion or promotion courses for adults. It should open up learning opportunities for all, for many different purposes - offering a second or third chance, satisfying the thirst for knowledge, beauty, or the desire to surpass oneself, or making it possible to broaden and deepen strictly vocational forms of training, including practical training. ${ }^{8}$

\section{REFERENCES}

1. Altbach, P. G. (Ed.). (1999). Private Prometheus: Private Higher Education and Development in the 21st Century. Contributions to the Study of Education No. 77. Connecticut: Greenwood Press.

2. $\quad$ Argyris, C., Putnam, R., \& Smith, D.M. (1985). Action science. San Francisco: Jossey-Bass 3-

3. Ayyar, R. V. V. (1996). Educational policy planning and globalisation. International Journal of Educational Development, 16(4), 347-354.

4. Bendit, R. and W. Gaiser (1995), Integration and Segregatio of Young People in a Changing World, Prospects, Vol. xxv, No.3, Sept

5. Brown, P. \& Lauder, H. (1996). Education, globalization, and economic development. Journal of Education Policy, 11(1), 1-25.

6. Brown, T. (1999). Challenging globalization as discourse and phenomenon. International Journal of Lifelong Education, 18(1), 3-17.

7. Cheng, Y.C. (2000). A CMI-Triplization Paradigm for Reforming Education in the New Millennium. International Journal of Educational Management. 14(4), 156-174.

8. Cheng, Y.C., Ng, K.H., \& Mok, M.M.C. (2002). Economic Considerations in Education Policy Making: A Simplified Framework. International Journal of Educational Management, 16(1), 18-39.

9. Fowler, F. C. (1994). The international arena: The global village. Journal of Education Policy, 9(5-6), 89102. Green, A. (1999). Education and globalization in Europe and East Asia: onvergent and divergent trends. Journal of Education Policy, 14(1), 55-71.

10. Henry, M., Lingard, B., Rizvi, F., \& Taylor, S. (1999). Working with/against globalization in education. Journal of Education Policy, 14(1), 85-97.

11. Holmes, W. (1999). The Transforming Power of Information Technology. Community College Journal, $70(2), \mathrm{pp} 10-15$.

12. ILO (2004), A Fair Globalization: Creating Opportunities for All, Geneva, International Labour Office

13. James, E. (1994). Public-private division of responsibility for education. In T. Husén \& T. N. Postlethwaite (Eds.), The international encyclopedia of education (2nd ed., Vol. 8,). Oxford, England/New York: Pergamon/Elsevier Science.

14. Jones, P. W. (1999). Globalisation and the UNESCO mandate: Multilateral prospects for educational development. International Journal of Educational Development, 19(1), 17-25.

15. Klor de Alva, J. (2000). Remaking the academy in the age of information. Issues in Science and Technology, 16(2), 52-58.

16. Lick, D. W. (1999). Transforming Higher Education: A New Vision, Learning Paradigm, and Change management. International Journal of Innovative Higher Education 1999, Fall, 13,

17. Little, A. W. (1996). Globalization and educational research: Whose context counts? International Journal of Educational Development, 16(4), 427-438.

18. McGinn, N. F. (1996). Education, democratization, and globalization: A challenge for comparative education.Comparative Education Review, 40(4), 341-357.

19. UNESCO (1996), Learning the Treasure Within, Paris, Co-publication Unesco/odile Jacob Publishers. 
20. UNESCO (1998), World Report on Education, Paris, UNESCO Publications.

21. Wang, Y. (2000) (ed.). Public-private partnerships in the social sector. Tokyo: Asian Development Bank Institute. Waters, M. (1995). Globalization. London: Routledge.

\section{ENDNOTES}

1. $\quad$ Bendit, R. and W. Gaiser (1995), P. 366.

2. UNESCO (1966).

3. Cheng, Y. C. (2000) and Brown, T. (1999).

4. ILO (2004).

5. Report on World Employment 1996-1999.

6. Art.26, Universal Declaration of Human Rights.

7. UNESCO World Report on Education 1998.

8. Unesco (1996), P. 111.

\section{NOTES}


NOTES 